УДК 624.137.7

05.00.00 Технические науки

МОДЕЛИРОВАНИЕ РАБОТЫ

ГЕОТЕХНИЧЕСКОГО БАРЬЕРА В СЛАБЫХ ГЛИНИСТЫХ ГРУНТАХ, УСТРАИВАЕМОГО ДЛЯ ЗАЩИТЫ СУЩЕСТВУЮЩИХ ЗДАНИЙ ОТ ВЛИЯНИЯ НОВОГО СТРОИТЕЛЬСТВА

Полищук Анатолий Иванович

д.-р техн. наук, профессор

SPIN-код=4301-1674, ofpai @ mail.ru

Межаков Александр Сергеевич

ассистент

SPIN-код=6348-4835, as.mezhakov@ gmail.com

Кубанский государственный аграрный

университет, Краснодар, Россия

Для уменьшения развития дополнительных осадок ленточных фундаментов существующего здания от влияния давления, передаваемого на грунт

основания новым близко расположенным плитным фундаментом рассматривается работа

геотехнического барьера в различных в грунтовых условиях. По первому варианту грунтовых условий (вариант 1) принято устройство геотехнического барьера в однородной толще слабого глинистого грунта. По второму варианту грунтовых условий (вариант 2) разделительное ограждение выполняется в толще двухслойного основания. При этом верхний слой основания (несущий) представлен слабым водонасыщенным глинистым грунтом, а второй (подстилающий) - малосжимаемым грунтом (супесью пластичной). По результатам моделирования и выполненных расчетов установлено, что наибольший положительный эффект при устройстве разделительного ограждения (геотехнического барьера) достигается в случае, когда основание является двухслойным. При этом нижняя часть геотехнического барьера должна быть заглублена в малосжимаемый грунт.

Дополнительная осадка ленточного фундамента существующего здания в однородном основании (вариант 1) при отсутствии геотехнического барьера составит примерно 8 см. В случае двухслойного основания (вариант 2) дополнительная осадка ленточного фундамента здания уменьшится на 80-85 $\%$ (на 6,6 см) и составит примерно 1,4 см

Ключевые слова: СУЩЕСТВУЮЩИЙ ЛЕНТОЧНЫЙ ФУНДАМЕНТ, СОСЕДНИЙ ВНОВЬ УСТРАИВАЕМЫЙ ПЛИТНЫЙ ФУНДАМЕНТ, ДОПОЛНИТЕЛЬНАЯ ОСАДКА, ГЕОТЕХНИЧЕСКИЙ БАРЬЕР, СЛАБОЕ ГЛИНИСТОЕ ОСНОВАНИЕ, ОДНОРОДНОЕ И ДВУХСЛОЙНОЕ ОСНОВАНИЕ

Doi: 10.21515/1990-4665-131-130
UDC 624.137 .7

Technical sciences

\section{MODELING OF GEOTECHNICAL BARRIER \\ IN WEAK CLAY SOILS ARRANGED TO PROTECT EXISTING BUILDINGS FROM IMPACT OF NEW CONSTRUCTION}

\author{
Polischuk Anatoly Ivanovich \\ Dr.Sci.Tech., Professor \\ RSCI SPIN-code=4301-1674, ofpai@ mail.ru
}

Mezhakov Alexander Sergeevich

Assistant

RSCI SPIN-code $=6348-4835$

as.mezhakov@gmail.com

Kuban State Agrarian University, Krasnodar, Russia

To reduce the development of additional settlement strip foundations of the existing building on the effect of pressure transmitted to a ground base located near the new slab foundation is considered the work of the geotechnical barrier in various ground conditions. In the first variant of soil, conditions (variant 1) made geotechnical barrier structure in a homogeneous thickness of the weak clay soil. In the second variant of soil conditions (variant 2), a separating barrier is performed in a two-layer base. The upper base layer (carrying) is shown a weak water-saturated clay soil, and the second (underlying) - low compressible soil (sandy loam plastic). According to the results of the calculations and modeling found that, the greatest positive effect on the separating barrier structure (geotechnical barrier) is achieved in the case when the base is a two-layer. The lower part of the geotechnical barrier must be recessed into the soil of low compressibility. Additional settlement strip foundation of the existing building in a uniform basis (variant 1) in the absence of geotechnical barrier is approximately $8 \mathrm{~cm}$. In the case of a two-layer base (variant 2), the additional settlement strip foundation building is reduced by $80-85 \%(6.6 \mathrm{~cm})$ and will make about 1.4 $\mathrm{cm}$

Keywords: EXISTING STRIP FOUNDATION, NEIGHBORING NEWLY ARRANGED SLAB FOUNDATION, ADDITIONAL SETTLEMENT, GEOTECHNICAL BARRIER, CLAY WEAK BASE, HOMOGENEOUS AND TWO-LAYER BASE 


\section{Введение}

Для снижения влияния нового строительства на осадки фундаментов близко расположенных существующих зданий применяются различные способы. К таким способам относится: устройство разделительных ограждений в виде готовых свай и шпунта; набивных свай, устраиваемых в грунте по различным технологиям; монолитных бетонных и железобетонных стенок (в том числе типа «стена в грунте») и другие. Из числа перечисленных способов особо следует выделить разделительное ограждение в виде геотехнического барьера, устраиваемого методом компенсационного нагнетания, которое получило наибольшее распространение в последние годы [1-3].

Последовательность работ по устройству геотехнического барьера заключается в следующем. До начала основных строительных работ первоначально производится цементация грунта через инъекторы, которые погружаются в грунт и образуют грунтоцементные сваи. Через инъекторы заполняются все имеющиеся полости, трещины, зоны пониженной плотности в основании (заполнительная цементация). При этом происходит уплотнение и армирование грунта линзами цементного раствора и создается более жесткая структура, способная реагировать на дальнейшее нагнетание цементного (инъекционного) раствора. Рассматриваемый способ устройства геотехнического барьера предложен специалистами НИИОСП им. Н.М. Герсеванова, защищен патентом РФ на изобретение (2006 г.), а его патентообладатель (НИИОСП им. Н.М.Герсеванова) удостоен диплома Правительства города Москвы $[4,6]$.

Отличительной особенностью данного способа является то, что геотехнический барьер - активная конструкция, с помощью которой можно оперативно влиять на состояние грунта основания фундаментов защищаемых зданий. Заполнительная цементация грунта через инъекторы и компенсационное (последующее) нагнетание осуществляются по 
манжетной технологии (с использованием специальной конструкции инъекторов) [6] небольшими объемами по 25 - 30 литров цементного или цементно- песчаного раствора с различными добавками. Главным условием при нагнетании является закачка требуемого количества раствора в нужную зону массива грунта. Заполнительная цементация производится при давлении от 0,1 до 0,3 МПа (давление увеличивается с увеличением глубины зоны закачки раствора) до начала работ по устройству фундамента здания (сооружения). Затем производятся циклы повторного (компенсационного) нагнетания при давлении нагнетания 0,5...2,0 МПа. Вертикальный геотехнический барьер рекомендуется применять для защиты фундаментов существующих зданий от влияния нового строительства; при устройстве близко расположенных глубоких котлованов, при прокладке тоннелей и другие.

a)

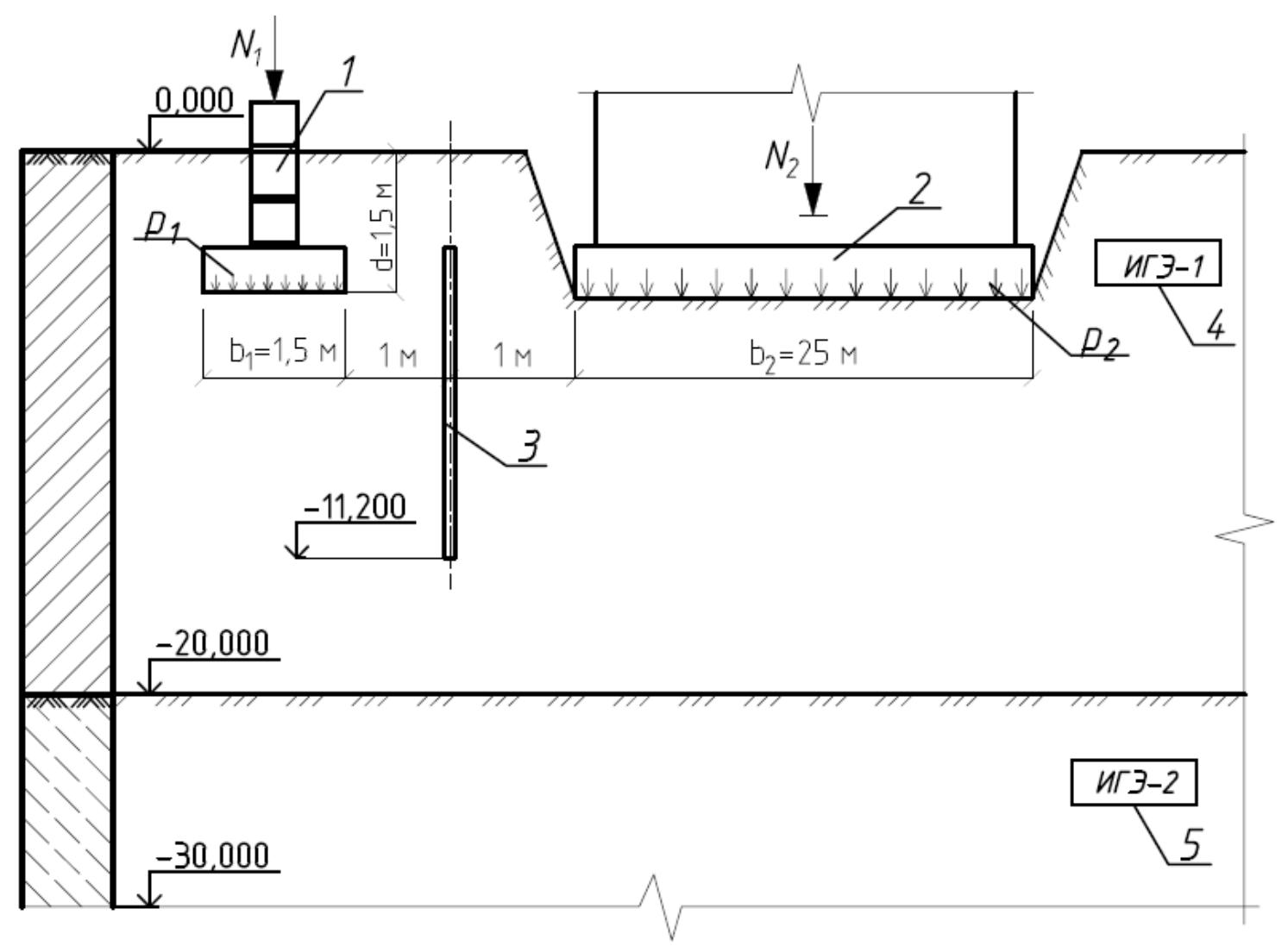


б)

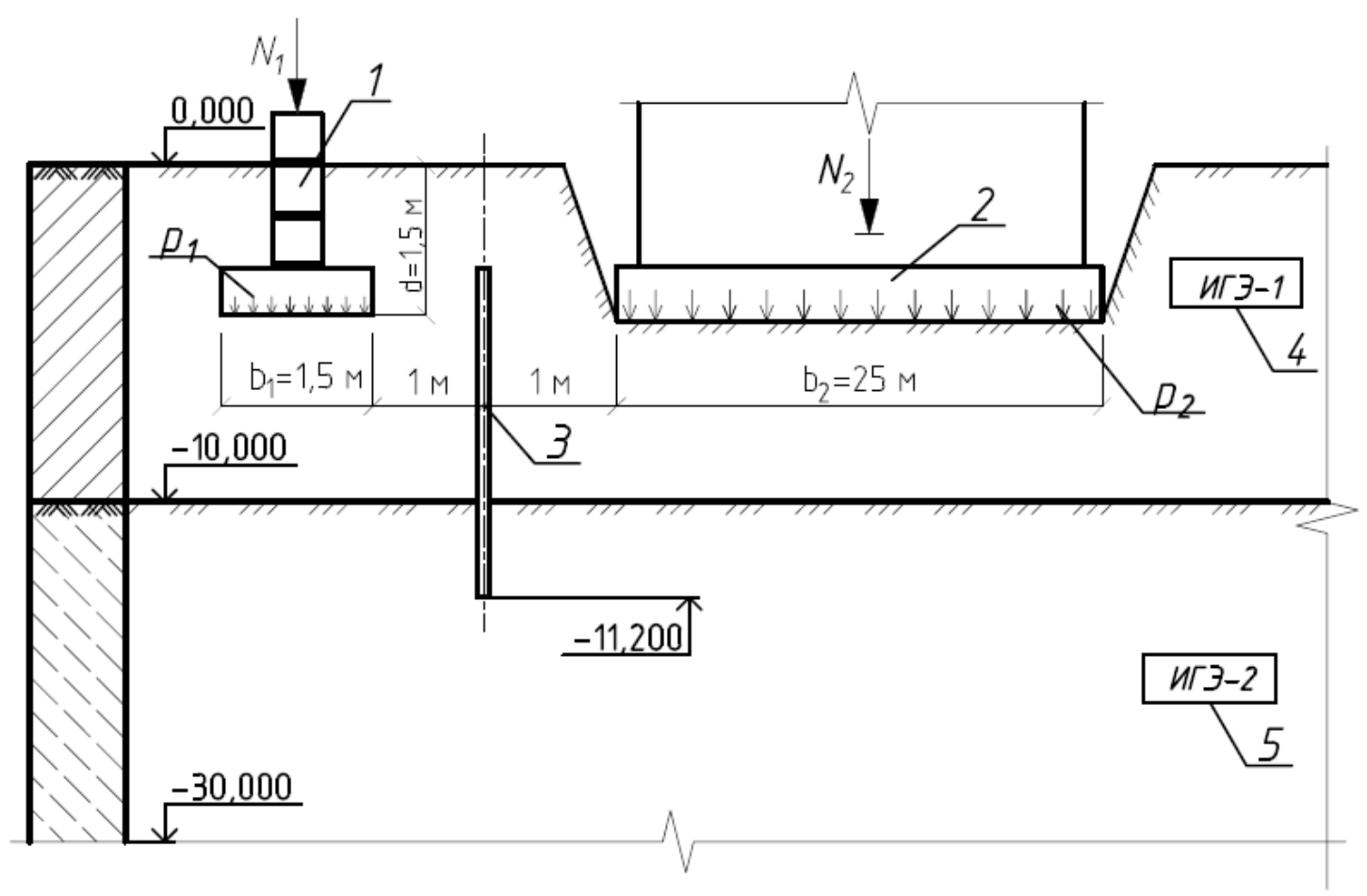

Рисунок 1 - Расчетная схема оценки влияния разделительного ограждения на осадки ленточного фундамента существующего здания для, $a$ - однородного и $б$ - двухслойного оснований:

1 - существующий ленточный фундамент; 2 - вновь устраиваемый соседний плитный фундамент; 3 - разделительное ограждение; $b_{1}, b_{2}-$ размеры подошвы фундаментов, м; $d$ - глубина заложения фундаментов, м; $p_{1}, p_{2}$ - давление по подошве фундаментов, кПа; $N_{1}, N_{2}$-нагрузка на фундаменты, кН; 4- инженерно-геологический элемент 1 (суглинок мягкопластичный); 5- инженерно-геологический элемент 2 (супесь пластичная)

\section{Грунтовые условия площадки строительства}

Рассмотрим работу разделительного ограждения (геотехнического барьера), устраиваемого вблизи ленточного фундамента существующего здания, при строительстве нового соседнего здания на плитном фундаменте. В качестве грунтовых условий принята площадка, сложенная 
слабым глинистым грунтом. Площадка состоит из двух слоев грунтового основания. Верхний слой (несущий) представлен суглинком мягкопластичным, второй (подстилающий) - супесью пластичной. Данные о мощности слоев основания по рассматриваемым вариантам представлены в табл. 1. Так как толща слабого глинистого грунта по варианту 1 является значительной $(20$ м) и распространяется ниже сжимаемой толщи, будем рассматривать ее как однородное основание. По варианту 2 основание рассматриваем как двухслойное. Основные физикомеханические характеристики грунтов основания представлены в табл. 2. Таблица 1 -Данные о мощности слоев основания строительной площадки

\begin{tabular}{|c|c|c|}
\hline \multirow{2}{*}{$\begin{array}{c}\text { Грунты основания площадки } \\
\text { строительства рассматриваемых зданий }\end{array}$} & \multicolumn{2}{|c|}{$\begin{array}{c}\text { Мощность слоя грунта, } \\
\text { залегащего в основании } \\
\text { фундамента, м }\end{array}$} \\
\cline { 2 - 3 } & вариант 1 & вариант 2 \\
\hline $\begin{array}{c}\text { Несущий слой (суглинок } \\
\text { мягкопластичный) }\end{array}$ & 20 & 10 \\
\hline $\begin{array}{c}\text { Подстилающий слой (супесь } \\
\text { пластичная) }\end{array}$ & 10 & 20 \\
\hline
\end{tabular}

Таблица 2 - Физико-механические характеристики грунтов основания строительных площадок зданий

\begin{tabular}{|c|c|c|}
\hline $\begin{array}{c}\text { Грунты основания фундаментов } \\
\text { зданий }\end{array}$ & $\begin{array}{c}\text { Суглинок } \\
\text { мягкпластичный } \\
\text { (ИГЭ-1) }\end{array}$ & $\begin{array}{c}\text { Супесь пластичная } \\
\text { (ИГЭ-2) }\end{array}$ \\
\hline Удельный вес $\gamma, \mathrm{\kappa H} / \mathrm{m}^{3}$ & 18,7 & 17,9 \\
\hline Удельное сцепление $c$, КПа & 12 & 10 \\
\hline Угол внутреннего трения $\varphi$, град. & 21 & 28 \\
\hline Коэффициент Пуассона $v$ & 0,35 & 0,33 \\
\hline $\begin{array}{c}\text { Модуль общей деформации } E, \\
\text { МПа }\end{array}$ & 7 & 25 \\
\hline
\end{tabular}




\section{Моделирование геотехнического барьера (разделительного ограждения) в программном комплексе Plaxis 2D}

При моделировании работы геотехнического барьера в слабом глинистом грунте (вариант 1) взаимодействие его боковой поверхности с грунтом задавалось с помощью понижающего коэффициента прочности, $R_{\mathrm{int}}=0,65$, а взаимодействие нижней части барьера $-R_{\mathrm{int}}=1$ [9-10]. Поведение геотехнического барьера представлено линейно-упругой моделью (LinearElastic), основными характеристиками которой являются модуль деформации $E$ и коэффициент Пуассона v. Модуль деформации материала геотехнического барьера вычислялся по формуле [5]:

$$
E_{2 б}=\frac{E_{c B} \times A_{c \beta}+E_{2 p} \times A_{2 p}}{A}
$$

где $E_{\text {гб }}$ - модуль деформации геотехнического барьера, МПа; $E_{c \varepsilon,} A_{c в}-$ модуль деформации грунтоцементной сваи (принят 800 МПа) и ее

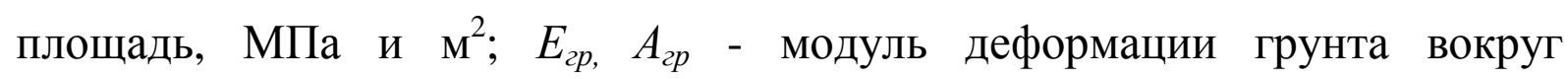
грунтоцементной сваи и его площадь, МПа и м²; $A$ - общая площадь геотехнического барьера, м². $^{2}$.

Принимая шаг грунтоцементных свай и ширину геотехнического барьера, равную 0,5 м (одна свая на погонный метр), получаем

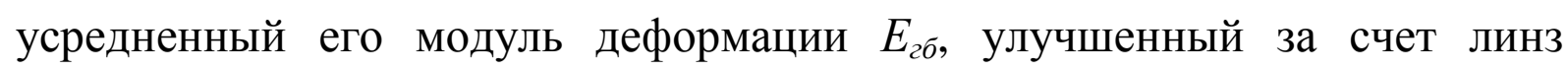
цементного камня, равный $E_{\text {гб }}=300$ МПа. Для глинистых грунтов при их цементации, как правило, принимают значение модуля деформации в пределах $E_{z p}=200-600$ МПа, что не противоречит принимаемому решению.

Расчет осадок ленточных фундаментов существующего здания и дополнительных его осадок от давления плитного фундамента соседнего здания производился в несколько этапов, учитывающих стадийность возведения рассматриваемых объектов $[7,8]$ : 
Этап 1. Моделирование процесса возведения существующего здания на ленточных фундаментах, определение напряжений в основании и его конечных осадок;

Этап 2. Моделирование процесса заполнительной цементации (первичного нагнетания цементного раствора) через инъекторы для устройства геотехнического барьера (разделительного ограждения) из грунтоцементных свай;

Этап 3. Моделирование процесса устройства котлована и соседнего (вновь устраиваемого) плитного фундамента;

Этап 4. Моделирование процесса компенсационного (повторного) нагнетания цементного или цементно-песчаного раствора через существующие инъекторы для объемного расширения грунтоцементного массива, (в программном комплексе Plaxis 2D объемное расширение корректировалось специальной опцией в пределах 2-10 \%);

Этап 5. Моделирование процесса передачи давления на грунт от соседнего (вновь устраиваемого) здания при действующих нагрузках на фундаментную плиту.

По результатам моделирования получены картины равных вертикальных перемещений (линии тока) в основании фундаментов рассматриваемых зданий (рис. 2-5). Представленные картины следует читать совместно со схемами, приведенными на рис. 1. 
a)

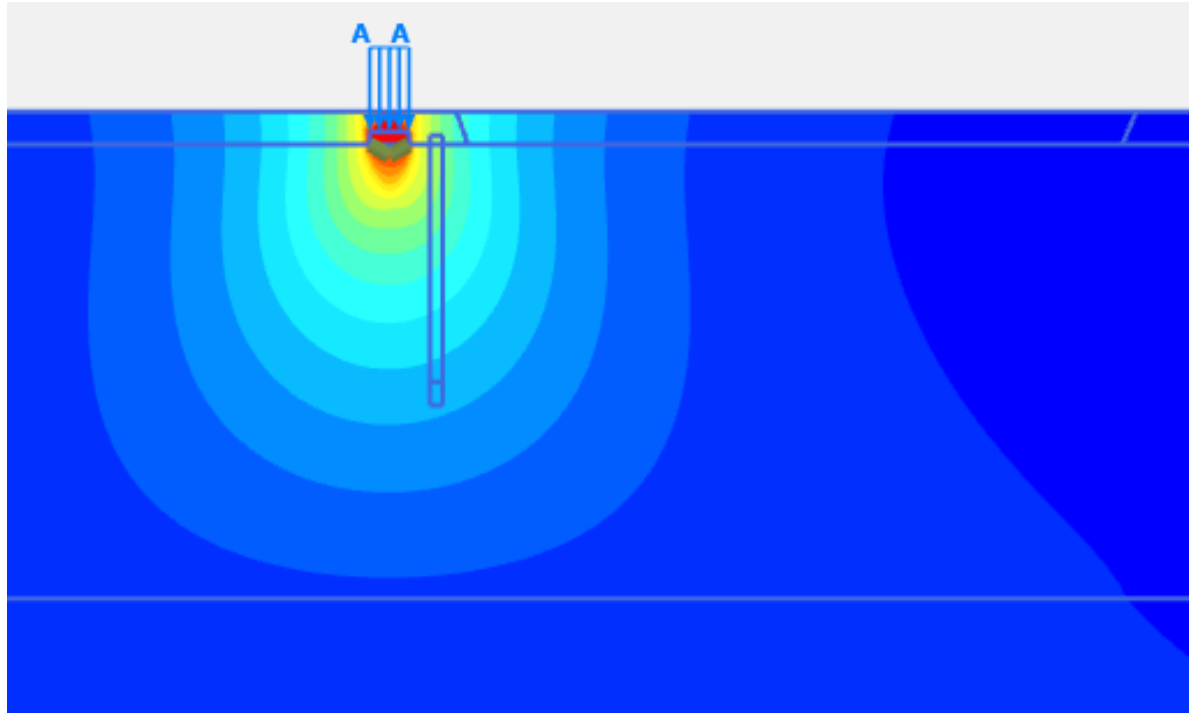

б)

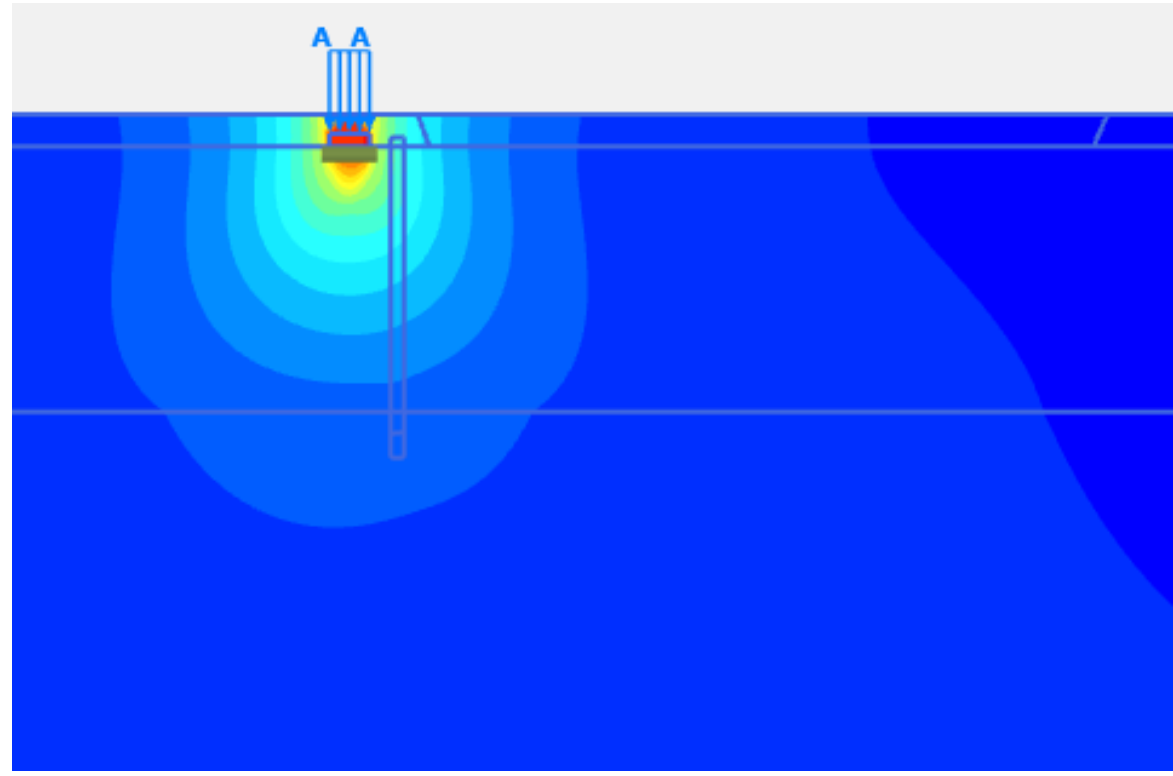

Рисунок 2 - Линии равных вертикальных перемещений (линии тока) в основании ленточного фундамента существующего здания

(соответствует этапу 1 - геотехнический барьер не работает, давление от соседнего, вновь устраиваемого, плитного фундамента отсутствует):

$a, \sigma-$ соответственно для однородного и двухслойного оснований 
a)

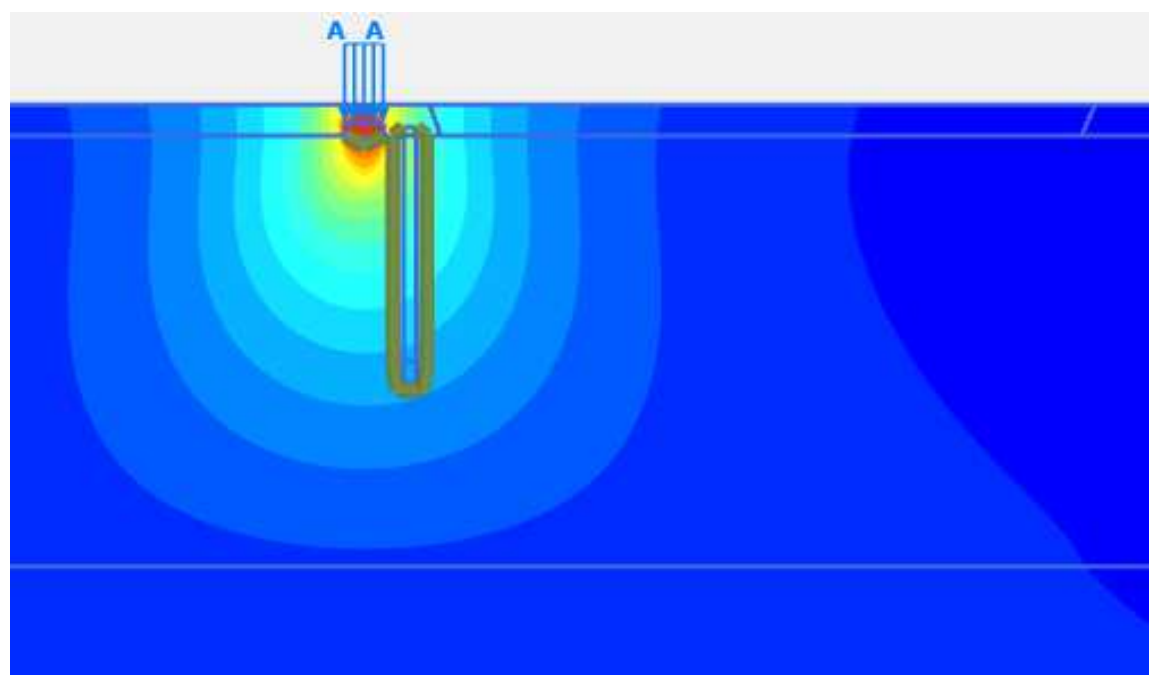

б)

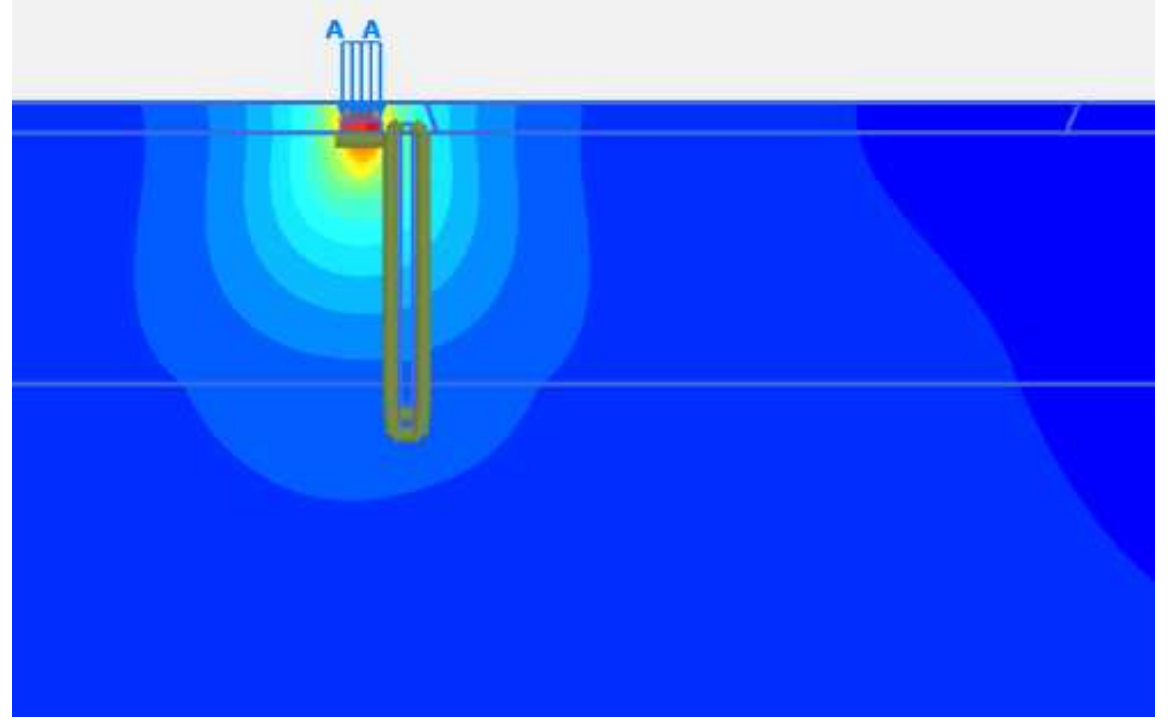

Рисунок 3 - Линии равных вертикальных перемещений (линии тока) в основании ленточного

фундамента существующего здания

(соответствует этапу 2 - геотехнический барьер включен в работу, давление от соседнего (редакция) фундамента отсутствует): $a, \sigma$ - соответственно для однородного и двухслойного оснований 
a)

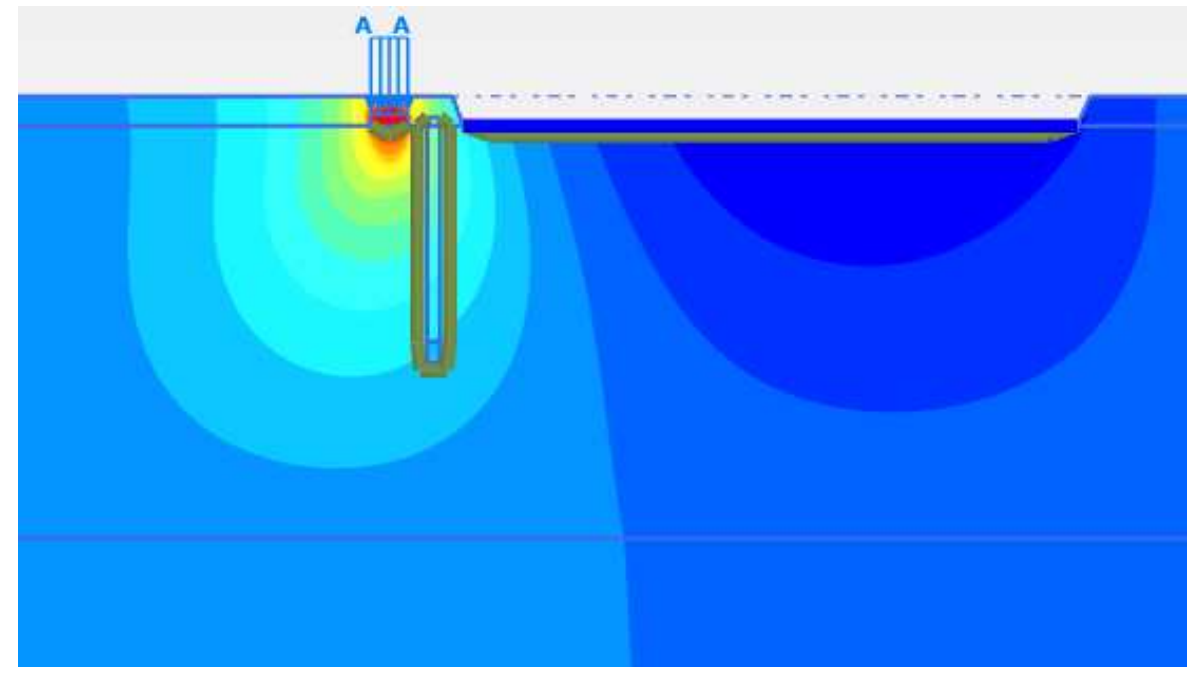

б)

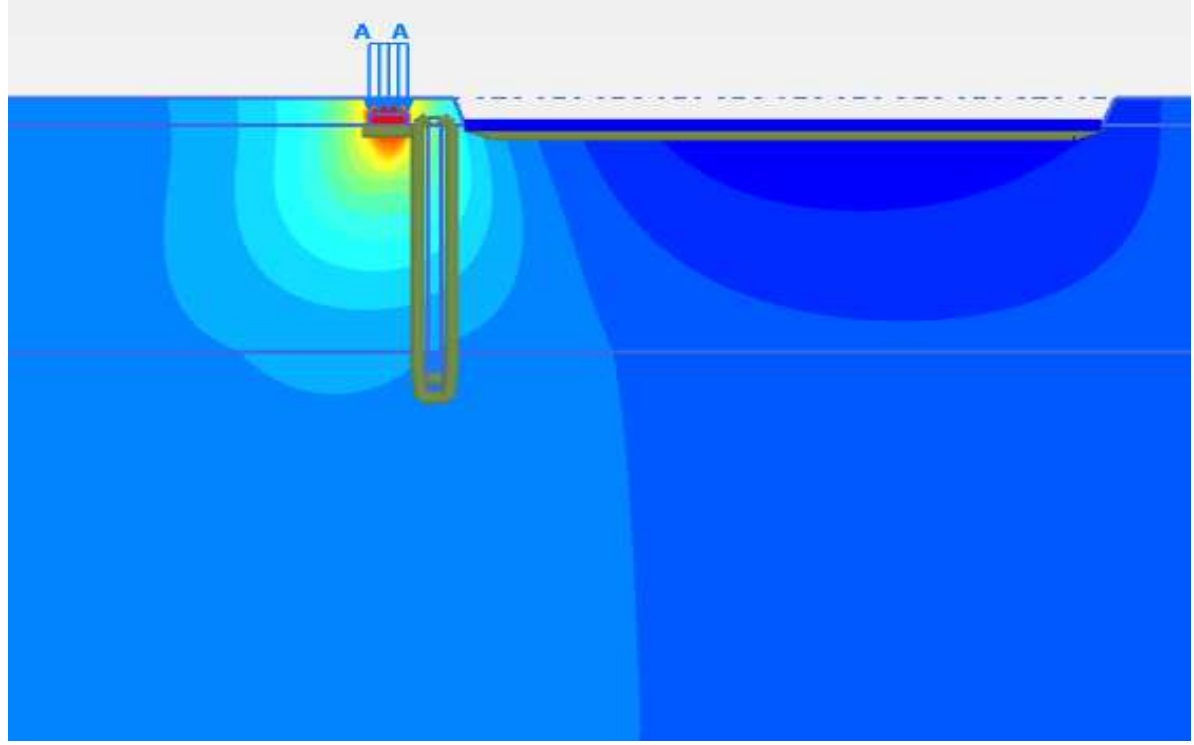

Рисунок 4 - Линии равных вертикальных перемещений (линии тока) в основании ленточного

фундамента существующего здания

(соответствует этапу 3 - геотехнический барьер включен в работу, на основание действует

нагрузка от веса фундаментной плиты):

$a, \sigma$ - соответственно для однородного и двухслойного оснований 
a)

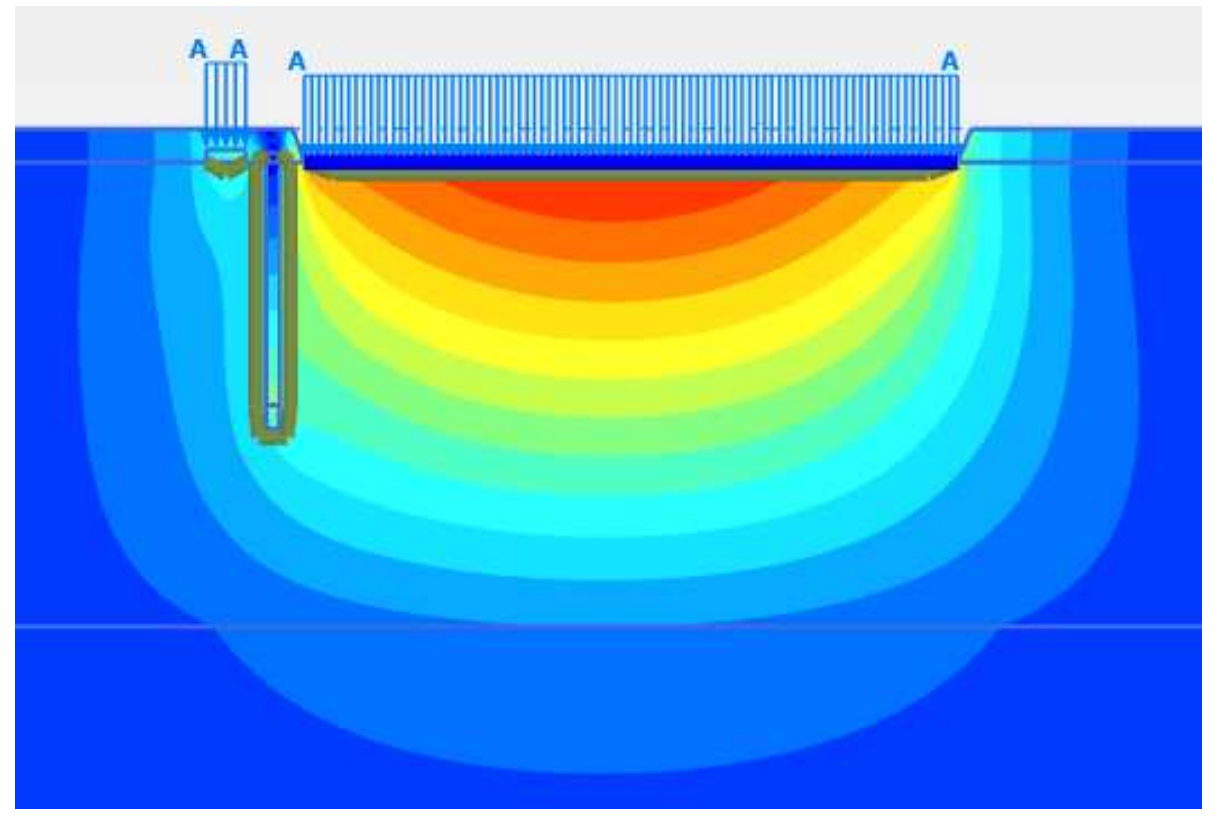

б)

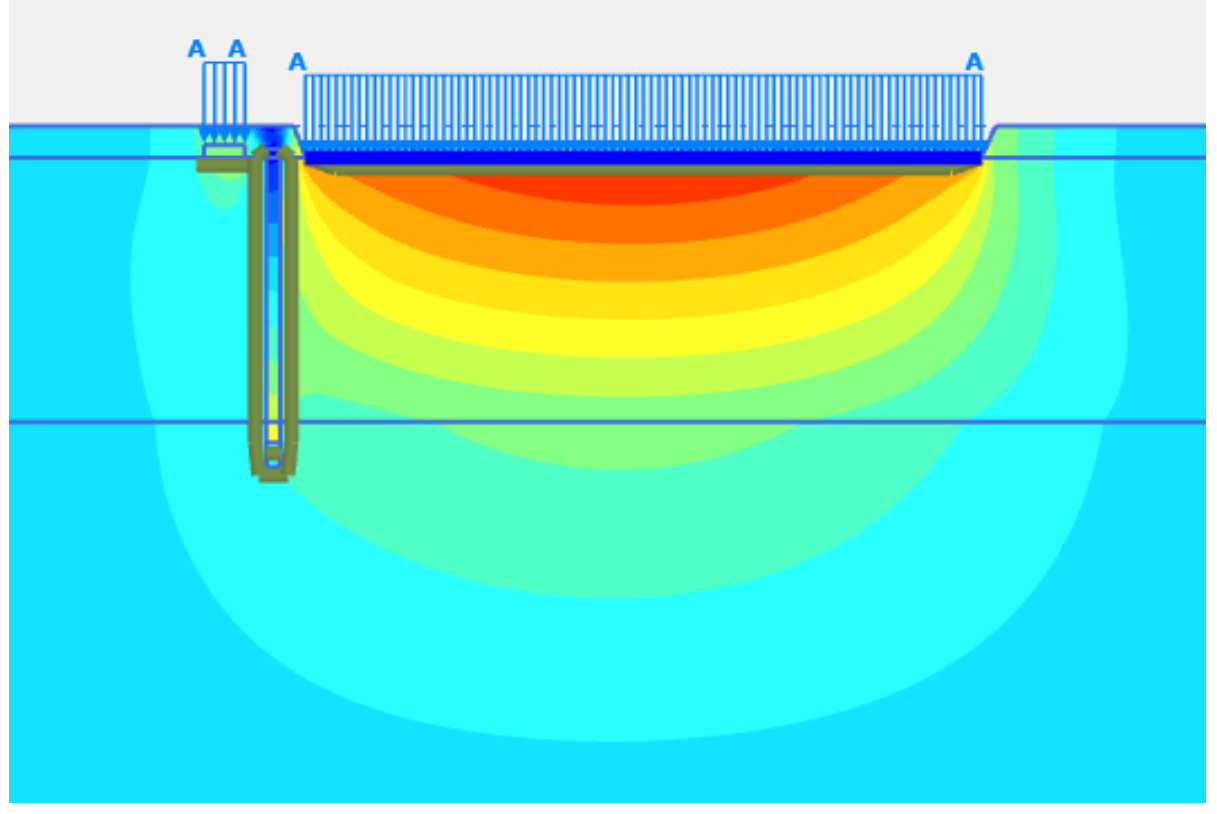

Рисунок 5 - Линии равных вертикальных перемещений (линии тока) в основании ленточного фундамента существующего здания

(соответствует этапу 5 - геотехнический барьер включен в работу, на основание действует полная нагрузка на плиту):

$a, \sigma$ - соответственно для однородного и двухслойного оснований 


\section{Анализ полученных результатов}

Для анализа результатов осадок ленточных фундаментов существующего здания в случае устройства геотехнического барьера (разделительного ограждения) были построены графические зависимости. При этом, анализировались приращения осадок ленточного фундамента существующего здания от давления по подошве соседнего (вновь устраиваемого) плитного фундамента (рис. 6).

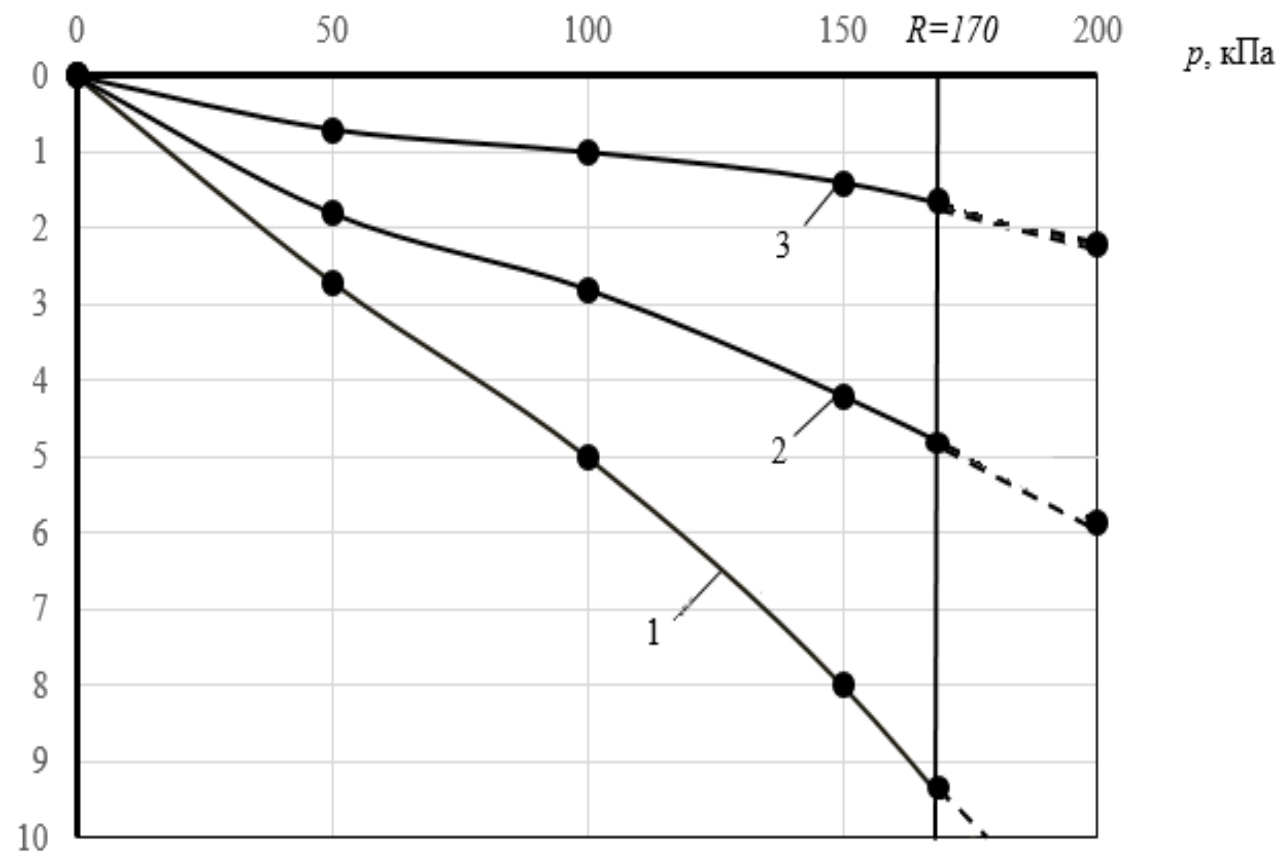

$\Delta \mathrm{S}, \mathrm{cM}$

Рисунок 6 - График зависимости дополнительных осадок ленточного фундамента (при $p=150$ кПа) существующего здания от давления по подошве соседнего (вновь устраиваемого) плитного фундамента

1 - дополнительная осадка ленточного фундамента без разделительного ограждения; 2 - то же при разделительном ограждении в виде геотехнического барьера в однородном основании; 3 - то же при разделительном ограждении в виде геотехнического барьера в двухслойном основании 
На основе полученных данных составлена таблица 3 результатов расчета приращений осадок ленточных фундаментов существующего здания при давлении по их подошве $p=150$ кПа (табл. 3). Из анализа

Таблица 3 - Данные об оценке приращений осадок ленточного фундамента существующего здания

\begin{tabular}{|c|c|c|c|c|c|}
\hline \multirow[t]{2}{*}{ Рассматриваемый случай } & \multirow[t]{2}{*}{$\begin{array}{c}\text { Осадка } \\
\text { ленточного } \\
\text { фундамента } \\
\text { существующего } \\
\text { здания ( } p=150 \\
\text { кПа), см }\end{array}$} & \multicolumn{2}{|c|}{$\begin{array}{c}\text { Приращение } \\
\text { осадки ленточного } \\
\text { фундамента от } \\
\text { давления, } \\
\text { передаваемого } \\
\text { соседним зданием: }\end{array}$} & \multicolumn{2}{|c|}{$\begin{array}{c}\text { Уменьшение } \\
\text { приращения осадки } \\
\text { существующего } \\
\text { фундамента за счет } \\
\text { устройства } \\
\text { разделительного } \\
\text { ограждения, \% }\end{array}$} \\
\hline & & $\mathrm{cm}$ & $\%$ & $\mathrm{cM}$ & $\%$ \\
\hline $\begin{array}{c}\text { Без устройства } \\
\text { разделительного } \\
\text { ограждения между } \\
\text { фундаментами }\end{array}$ & \multirow{3}{*}{6,5} & 8 & 120,0 & - & - \\
\hline $\begin{array}{c}\text { Устройство } \\
\text { разделительного } \\
\text { ограждения в } \\
\text { однородном основании }\end{array}$ & & 4,2 & 65,0 & на 3,8 & на $45-50$ \\
\hline $\begin{array}{c}\text { Устройство } \\
\text { разделительного } \\
\text { ограждения в } \\
\text { двухслойном основании }\end{array}$ & & 1,4 & 21,0 & на 6,6 & на $80-85$ \\
\hline
\end{tabular}

полученных данных (рис. 6, табл. 3) следует, что осадка ленточного фундамента существующего здания без учета влияния давления от соседнего плитного фундамента составит примерно 6,5 см. Если же рядом устраивается соседний плитный фундамент с давлением по подошве $p=150$ кПа (в период его эксплуатации), то приращение осадки (дополнительная осадка) существующего ленточного фундамента составит 8 см (120 \% к существующей его осадке) при условии, что никакие защитные мероприятия между фундаментами не предусмотрены. В случае двухслойного основания (вариант 2) дополнительная осадка ленточного фундамента здания уменьшится на 80-85 \% (примерно на 6,6 см) и составит 1,4 см. В однородном основании (вариант 1) дополнительная 
осадка ленточного фундамента уменьшится на 45-50 \% (примерно на 3,8 см), следовательно, составит примерно 4,2 см.

\section{Основные выводы}

1. Выполненные расчеты позволили установить, что наибольший эффект по уменьшению дополнительной осадки ленточных фундаментов существующих зданий при устройстве разделительного ограждения (геотехнического барьера) между зданиями достигается в том случае, когда нижняя часть барьера опирается на малосжимаемый грунт. В этом случае уменьшение дополнительной осадки существующего ленточного фундамента достигает до 80-85\% при отсутствии разделительного ограждения.

2. Установлено, что даже при наличии значительной толщи слабого глинистого грунта (15-20 м) в основании разделительное ограждение (геотехнический барьер) между фундаментами обеспечивает защиту существующих зданий от влияния нового строительства. Уменьшение дополнительной осадки ленточных фундаментов составляет до 45-50\% при отсутствии разделительного ограждения.

\section{Список использованной литературы}

1. Справочник геотехника: основания, фундаменты и подземные сооружения. Под общей редакцией Ильичева В.А. и Мангушева Р.А. / Глава 16. Усиление оснований и фундаментов зданий и сооружений: автор - А.И.Полищук. - М.: Изд-во АСВ, 2014 - С. 627-666.

2. Основания и фундаменты. Ч. 2. Основы геотехники: Учебник / Авторы: Б.И. Далматов, В.Н. Бронин, В.Д. Карлов, Р.А. Мангушев, И.И. Сахаров, С.Н. Сотников, В.М. Улицкий, А.Б. Фадеев. М.: Изд. АСВ; СПБГАСУ, 2002. - 392 с.

3. Полищук А.И. Основы проектирования и устройства фундаментов реконструируемых зданий. 3-е изд., доп. - Нортхэмптон: STT; Томск: STT, 2007. - 476 c.

4. СТО 36554501-007-2006. Проектирование и устройство вертикального или наклонного геотехнического барьера методом компенсационного нагнетания. ФГУП «НИЦ «Строительство», г. Москва, 2006 г. - 21 с.

5. Ю. Л. Винников, А.В. Веденисов. Модельные исследования эффективности грунтоцементных разделительных экранов для защиты зданий от влияния нового строительства. // Вестник ПНИПУ. Строительство и архитектура №1, 2015 г. - С. 51-63 
6. Разводовский Д.Е., Шулятьев О.А., Никифорова Н.С. Оценка влияния нового строительства и мероприятия по защите существующих зданий и сооружений. // РАСЭ том XII «Строительство подземных сооружений». ОАО «ВНИИНТПИ», г. Москва, 2008 г. - С. 230-239.

7. Полищук А.И., Межаков А.С. Совершенствование способов устройства фундаментов вблизи существующих зданий. // Вестник ПНИПУ. Строительство и архитектура № 3, 2014 г. - С. 143-148.

8. Полищук А.И., Межаков А.С. Оценка влияния разделительной шпунтовой стенки в глинистых грунтах на осадки фундаментов существующих зданий // Механика грунтов в геотехнике и фундаментостроении. Южно-Российский государственный политехнический университет (НПИ) имени М.И. Платова. - Новочеркасск: ЮРГПУ (НПИ), 2015. - С. 366-371.

9. Программный комплекс Plaxis 2D. Сборник лекционных и практических занятий. - Санкт-Петербург, 2010 г. - 105 с.

10. Парамонов В.Н. Метод конечных элементов при решении нелинейных задач геотехники. - СПб: Геореконструкция, 2012 - 262 с.

\section{References}

1. Spravochnik geotekhnika. Osnovaniia, fundamenty i podzemnye sooruzheniia. Glava 16. Usilenie osnovanii i fundamentov zdanii i sooruzhenii. Pod obschei redaktsiei Il'icheva V.A. i Mangusheva R.A.- M.: Izd-vo ASV, 2014 - pp. 627-666

2. Osnovaniia i fundamenty. Ch. 2. Osnovy geotekhniki: Uchebnik / Avtory: B.I. Dalmatov, V.N. Bronin, V.D. Karlov, R.A. Mangushev, I.I. Sakharov, S.N. Sotnikov, V.M. Ulitskii, A.B. Fadeev. M.: Izd. ASV; SPBGASU, 2002. - 392 s.

3. Polischuk A.I. Osnovy proektirovaniia i ustroistva fundamentov rekonstruiruemykh zdanii. 3-e izd., dop. - Nortkhempton: STT; Tomsk: STT, 2007. - 476 s.

4. STO 36554501-007-2006. Proektirovanie i ustroistvo vertikal'nogo ili naklonnogo geotekhnicheskogo bar'era metodom kompensatsionnogo nagnetaniia. FGUP «NITs «Stroitel'stvo», g. Moskva, 2006 g. - 21 s.

5. Razvodovskii D.E., Shuliat'ev O.A., Nikiforova N.S. Otsenka vliianiia novogo stroitel'stva i meropriiatiia po zashchite sushchestvuiushchikh zdanii i sooruzhenii. // RASE tom KhII «Stroitel'stvo podzemnykh sooruzhenii». OAO «VNIINTPI», g. Moskva, 2008 g. pp. 230-239.

6. Iu. L. Vinnikov, A.V. Vedenisov. Model'nye issledovaniia effektivnosti gruntotsementnykh razdelitel'nykh ekranov dlia zashchity zdanii ot vliianiia novogo stroitel'stva. // Vestnik PNIPU. Stroitel'stvo i arkhitektura №1, 2015 g. - pp. 51-63.

7. Polischuk A.I., Mezhakov A.S. Otsenka vliianiia razdelitel'noi shpuntovoi stenki v glinistykh gruntakh na osadki fundamentov sushchestvuiushchikh zdanii // Mekhanika gruntov $\mathrm{v}$ geotekhnike $\mathrm{i}$ fundamentostroenii. Iuzhno-Rossiiskii gosudarstvennyi politekhnicheskii universitet (NPI) imeni M.I. Platova. - Novocherkassk: IuRGPU (NPI), 2015. - pp. 366-371.

8. Polishchuk A.I., Mezhakov A.S. Sovershenstvovanie sposobov ustroistva fundamentov vblizi sushchestvuiushchikh zdanii. // Vestnik PNIPU. Stroitel'stvo i arkhitektura № 3, 2014 g. - pp. 143-148

9. Programmnyi kompleks Plaxis 2D. Sbornik lektsionnykh i prakticheskikh zaniatii Sankt-Peterburg, 2010 g. - 105 s.

10. Paramonov V.N. Metod konechnykh elementov pri reshenii nelineinykh zadach geotekhniki. - SPb: Georekonstruktsiia, 2012 - 262 s. 